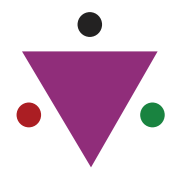

IJCRR

Section: Healthcare Sci. Journal Impact Factor: 6.1 (2018) ICV: 90.90 (2018)

\title{
A Study of Clinical and CSF Characteristics in Cases of Acute Meningoencephalitis in Immunocompetent Adults in a Tertiary Care Hospital of Eastern India
}

\section{Md. Hamid Ali ${ }^{1}$, Sinjan Ghosh ${ }^{2}$, Nandini Chatterjee ${ }^{3}$, Udas Chandra Ghosh4}

\begin{abstract}
'Department of General Medicine, Murshidabad Medical College and Hospital, West Bengal, India; 'Department of Neurology, NRS Medical College and Hospital, West Bengal, India; ${ }^{3}$ Department of General Medicine, IPGMER, West Bengal, lndia; ${ }^{4}$ Department of General Medicine, Murshidabad Medical College and Hospital, West Bengal India.
\end{abstract}

\section{ABSTRACT}

Meningoencephalitis is a very critical illness that is widespread andit remains a major cause of mortality and morbidity with neurological disabilities. It usually presents with varying degrees of symptoms of meningeal inflammation, posing difficulties in diagnosis and treatment. Study was conducted to Evaluate clinical severity and CSF(cerebrospinal fluid) findings at presentation. Encompassing the clinical status, CSF assays, along with revelations of recent trends of infection responsible formeningoencephalitis, this study also shows that early confirmation of clinical suspicion with judgement of severity \& CSF study, is of great significance. Prompt diagnosis providesphysicians with an opportunity to prevent undue mortality and morbidity.. Here lies therelevance of this study.

Key Words: Acute Meningoencephalitis, Cerebrospinal fluid, MRI of brain

\section{INTRODUCTION}

The incidence of acute encephalitis in western countries is 7.4 cases per100,000 population per year. In tropical countries, the incidence is 6.34 per 100,000 per year. ${ }^{[3]}$ Herpes simplex encephalitis has an incidence of $2-4$ per million population per year. ${ }^{[4]}$ The common pathogens which are encountered in adult bacterial meningitis are Streptococcus pneumoniae $(30-50 \%)$, Neisseria meningitidis $(10-35 \%)$, Staphylococci (5-15\%), other Streptococcus species, Haemophilus influenza (1-3\%), Gram negative bacilli (1-10\%) and Listeria monocytogenes ${ }^{[4]}$. Prompt recognition, early diagnosis, efficient decision making followed byrapid institution of therapy plays a pivotal role in saving a large salvageable portion of the affected population and thus reducing mortality. Tuberculous meningitis (TBM) remains the most common presentation. In spite of advances in diagnostic technology and effective therapeutic options, it continues to pose significant management challenges. Despite anti-TB chemotherapy, $20-50 \%$ of the affected people die and many who survive have significant neurological deficits. The case fatality noted to be associated significantly with delay in diagnosis and treatment. Tuberculous meningitis (TBM) generally occur in course of a sub acute or chronic case but TBM may have an acute presentation. The duration of presenting symptoms may vary from 1 day to 9 months, although several cases may present with symptoms of less than 2 weeks duration. Diagnostic evaluation includes various microbiological, pathologic, molecular, and biochemical investigations \& imaging modalities. Imaging helps in early diagnosis and helps in preventing morbidity and mortality. ${ }^{[5]}$

\section{Corresponding Author:}

Dr. Sinjan Ghosh, Department of Neurology, Nil Ratan Sircar Medical College and Hospital, Kolkata 14, West Bengal, India.

ISSN: 2231-2196 (Print)

Received: 02.10 .2019
ISSN: $0975-5241$ (Online)

Revised: 20.10 .2019
Accepted: 05.11.2019 


\section{Aims and objectives of these studies}

Evaluation of clinical severity and CSF(cerebrospinal fluid) findings at presentation in Acute Meningoencephalitis.

\section{MATERIALS AND METHODS}

a) Patients, who were admitted in between January 2013-August 2014 in the department of General Medicine of NRS Medical College and Hospital from rural and urban catchment area, were included in this study as simple random selection. 50 patients, aged $>12$ years were included in this prospective observational study with Fever and Signs of Meningitis (Nuchal rigidity, vomiting, and headache) or Signs of meningoencephalitis: Meningeal signs with altered sensorium, focal neuro-deficits, and seizures. The following patients with Sepsis, Metabolic Encephalopathy, Dyselectrolytemia, Poisoning, Cerebrovascular Accident, Intracranial SOL, Neurocysticercosis, Enteric Fever with meningism, Vascular Aneurysms producing local compressive effect, Acute disseminated Encephalomyelitis (ADEM) and Cerebral Malaria were excluded from the study. Clinical Characteristics-Glasgow Coma Scale(GCS) Scoring( 3 to 15) as a marker of clinical severity on admission. According to the score calculated on admission, patients divided into three groups-Gr. A(GCS 3-5), Gr. B (GCS 6-9), Gr. C (GCS 10-15). : The macroscopic appearance of the CSF recorded. A routine CSF total and differential count were done by a haemocytometer by standard methods. The CSF samples subjected to a cytospin by using Shandon cytospin MODEL 001/ 002. Gram stained of CSF was done and examined under microscope. ZN staining, Bacterial culture, TB culture (BACTEC) and Cryptococcal staining(India Ink Stain) were also done. Specific viral analysis was done by ELISA according to relevance, availability and feasibility. All CSF samples were cultured on Sheep blood agar, Chocolate agar, MacConkey's agar and Thioglycollate broth for specific diagnosis. Neuroimaging may precede CSF study by lumbar puncture if there is any contraindication to the procedure like history suggestive of presence of Intracranial SOL, Papilloedema, focal neurodeficits, and signs of increased intracranial tension or new onset seizures. We used laboratory methods available in the Hospital and NABL accredited private laboratory. It was a Simple observational study. History taking and Meticulous Clinical Examination \& HaematoPathological and Biochemical Investigations: including complete blood count, Fasting and Post Prandial Glucose, Blood Urea and Creatinine, Serum Sodium and Potassium, Blood Culture study, HIV 1\& 2, HBs $\mathrm{Ag}$ and Anti HCV Antibody, Malaria dual antigen,
Dengue Ns1 antigen and Dengue specific IgG and IgM, Widal's Test, Leptospira specific IgM antibody. CSF was analysed for a) Cytology-Cell type and Cell count, b) Biochemistry- Glucose, Protein and Chloride and c) Microbiology-Gram staining, ZN staining, Bacterial culture, TB culture(BACTEC) and Cryptococcal staining(India Ink Stain) d) Specific Viral analysis by CSF ELISA according to relevance, availability and feasibility. Final Diagnosis Based on Set Criteria and Segregation of cases according to etiological groups from CSF and MRI findings. Descriptive statistical methods were used, utilizing the SPSS software for data analysis.

\section{REVIEW OF LITERATURE}

Mortality of acute bacterial meningitis is $25 \%$. Morbidity in the tem of neuro-deficit is also very high. Now are going through the advanced stage of antibiotic era \& critical care facility. In spite of that we are facing increased mortality. The prognosis is worse with a delay in management. ${ }^{[6]}$ Increased morbidity and mortality is seen in both high and low-income group \&countries.$^{[5]}$ It is very tough job to select patients for timely antibiotic administration in emergency room. ${ }^{[7]}$

Schutte CM and Van der Meyden $\mathrm{CH}$ in their study found good correlation between both the GCS and CSF-protein level at admission and the outcome of patients with meningitis was found. With the GCS value being a better prognostic indicator than high CSF protein levels. ${ }^{[8]}$ Syamal Modi and Amit Kumar Anand in their study found Streptococcus pneumonia was the most common pathogen which was isolated in $120(60 \%)$ culture positive cases. Cell counts showed the predominance of neutrophils in all cases with $\mathrm{ABM}$. In ABM protein is high \& sugar is low. ${ }^{[9]}$ Gram staining is one of the cornerstones methods in diagnosing $\mathrm{ABM}$ in developing countries.

Mani R, Pradhan S et al in their study conducted in South India (NIMHANS) in $2007{ }^{[10]}$ observed that, as compared to Western studies, the relative incidence of meningitis caused by $\mathrm{H}$. influenza, $\mathrm{N}$. meningitides and Listeria is less in South-East Asia. On the contrary, gram negative bacilli such as Klebsiella pneumonia and Pseudomonas aeruginosaare increasingly being recognised as important pathogens of community-acquired as well as nosocomial meningitis especially among the elderly and in patients with chronic debilitating diseases like cirrhosis, diabetes and malignancies. [11]. Steiner, H. Budka et al in their review of diagnosis and management recommendations in Viral encephalitis states that analysis of CSF for protein and glucose contents, cellular analysis and identification of the pathogen by biotechnology method like PCR polymerase chain reaction (PCR) and serology-Hospitalisation is mandatory with ICCU facility [21] . Combinations of meningitis/ encephalitis and myelitis/ 
radiculitis are associated with Epstein Barr Virus (EBV); myelitis with VZV, CMV, EBV, and HSV-2; and ventriculitis/encephalitis with VZV and CMV. Brainstem encephalitis due to HSV and VZV, and poly myeloradiculitis due to CMV are well documented. Recent large CSF PCR studies have shown that VZV, EBV, and CMV more frequently produce meningitis, encephalitis, or encephalopathy in immunocompetent hosts than was formerly realized. ${ }^{[12]}$

A study conducted by Rathore SK, Dwibedi B et al during April 2011 to July 2012. Blood and CSF samples of 526 AES cases are investigated by serology and/or PCR. Viral aetiology was identified in $91(17 \cdot 2 \%)$ cases. Herpes simplex virus (HSV; types I/ II) was most common (16.1\%), followed by measles $(2 \cdot 6 \%)$, Japanese encephalitis virus $(1 \cdot 5 \%)$, dengue virus $(0 \cdot 57 \%)$, varicella zoster virus $(0 \cdot 38 \%)$ and enteroviruses $(0 \cdot 19 \%)$. Simultaneous infection of HSV-I and measles were observed in seven cases. This report provides the first evidence on viral aetiology of acute encephalitis syndrome viruses from eastern India showing dominance of HSV that will be useful in informing the public health system. ${ }^{[13]} \mathrm{How}-$ ever, measurement of antibodies in single specimen of serum and CSF lacks sensitivity; they interpreted the positivity (positive for IgM and/or IgG antibody) in relation to other supportive clinical, electroencephalographic and neuro-radiological evidences. CSF-PCR is the diagnostic test of choice, which has sensitivity rate as high as $98-99 \%$ and specificity of $100 \%$., ${ }^{[14]}$. HSE is the only form of sporadic encephalitis which has a specific antiviral therapy i.e. acyclovir., ${ }^{[15]} \mathrm{F}$. Frantzidou, F. Kamaria et al found in their study that Entero viruses was the most common cause of adult aseptic meningitis and together with HSV-1 the main causes of encephalitis. ${ }^{[16]}$.

\section{RESULTS AND ANALYSIS}

GENDER DISTRIBUTION: (Figure 1\&Chart 1) All immune-competent patients aged $12 \mathrm{yrs}$ or more were selected randomly over a period of 19 months for this observational study as per the clinical inclusion criteria.18 cases (36\%) were male and 32 cases (64\%) were female. Patients ranging from ages 12 yrs to $77 \mathrm{yrs}$ were selected and divided into age groups. Maximum number of patients (26\%) belonged to $12-$ 20 yrs age group.

Groups according to the Glasgow coma Scale: (See Figure 4 \& Chart 2)The patients were clinically examined and classified into three groups according to the Glasgow coma scale. 15 cases (30\%) belonged to group A(GCS 3 to 5), 22 cases(44\%) Belonged to Gr. B(GCS 6 to 9) while 13 cases (26\%) belonged to Gr. C (GCS 10 to 15 ) on admission, 30\% patients had a very poor clinical condition (GCS 3 to 5) during admission as evident from the GCS category distribution while majority of patients belonged to group B. ( See table2 \& Chart 2)
Etiological groups\& gender distribution: (See Figure 2\& Chart 3) After obtaining the investigation results the cases were segregated into etiological groups and Re classified according to the GCS groups and gender. Majority of cases had a viral aetiology (56\%) followed by tuberculous $(28 \%)$ and bacterial aetiology (16\%). Pyogenic meningitis cases had a Male predilection (62.5\%) while tuberculous and viral meningitis had female predilection in incidence, $57.14 \%$ and $75 \%$ respectively.

Distribution according to age groups: (See Figure $3 \&$ Chart 5)

Majority of pyogenic meningitis cases (37.5\%) belonged to 31-40yrs age group while maximum number of tuberculous meningitis cases (35.71\%) and viral Meningoencephalitis cases $(28.57 \%)$ belonged to $12-20$ yrs age group. Out of 50 cases 8 cases $(16 \%)$ were diagnosed as pyogenic meningitis[ 5 males $(62.5 \%)$ and 3 females $(37.5 \%)$ ]

Distribution of Patients according to GCS on admission: (See figure $4 \&$ Chart 6) 1case was in gr A(GCS 3 to 5), 5 cases in gr B(GCS 6 to 9) and 2 cases were in gr C(GCS 10 to 15$)$. So $12.5 \%$ cases presented in a clinically severe state(GCS 3 to 5) during admission.14 cases(28\%) were diagnosed as tuberculous meningitis[ 6 males $(42.86 \%)$ and 8 females(57.14\%)] 6 cases were in gr A(GCS 3 to 5), 6 cases in gr B(GCS 6 to 9) and 2 cases were in gr C(GCS 10 to 15$)$. $42.86 \%$ cases presented in a clinically poor condition(GCS 3 to 5) on admission. (See table $5 \&$ Chart 5) 28 cases (56\%) were diagnosed as viral meningoencephalitis. [ 7 males (25\%) and 21 females(75\%)] 8 cases were in Gr A(GCS 3 to 5), 11 cases in $\mathrm{Gr} \mathrm{B}(\mathrm{GCS} 6$ to 9)and 9 cases were in Gr. C(GCS 10 to 15$) 28.57 \%$ cases presented in a clinically poor state(GCS 3 to 5) on admission.

\section{Classification according to ges in different etiological groups:(See Figure 5)}

After comparative analysis of three etiological groups and their GCS categories it was found that tuberculous meningitis cases $(42.8 \%)$ presented in a more severe state followed by cases of viral meningoencephalitis $(28.57 \%)$ and pyogenic meningitis(12.5\%).

\section{CSF Findings}

Cytology: Cell Count \& Cell Type: (See Figure 5 \& Chart $7 \& 8)$

In cases that were later diagnosed as pyogenic meningitis, the cell counts ranged from 120 to

5900 cells/cumm with a mean count of $950.5 \pm 3748.84$ cells/cumm and neutrophil predominance. In cases with a final diagnosis of tuberculous meningitis, the cell counts ranged from 60 to 460 cells/cumm with a mean count of $225.86 \pm 217.22$ cells/cumm with a lymphocyte predomi- 
nance. In cases categorized as viral meningoencephalitis, the cell counts ranged from 30 to 510 cells/cumm with a mean count of $128.607 \pm 276.86$ cells/cumm and a predominantly lymphocytic picture.

\section{Biochemistry \& ADA levels: (See Figure 6 \& Chart 9)}

Pyogenic meningitis cases revealed a mean CSF glucose of $19 \pm 18.9 \mathrm{mg} / \mathrm{dl}$,mean protein levels of $62.375 \pm 48.52 \mathrm{mg} /$ $\mathrm{dl}$, mean chloride levels of $112.88 \pm 12.48 \mathrm{meq} / \mathrm{Lt}$ with mean ADA level of $8.025 \pm 24.14$. This picture was consistent with hypoglycorrhachias expected in pyogenic meningitis. Tuberculous meningitis cases revealed a mean CSF glucose of $35.79 \pm 22.9 \mathrm{mg} / \mathrm{dl}$, mean protein levels of $268.86 \pm 368.12$ $\mathrm{mg} / \mathrm{dl}$, mean chloride levels of n112.714 $\pm 12.54 \mathrm{meq} / \mathrm{Lt}$ with mean ADA level of $16.29 \pm 16.14$ U/L. Protein levels were markedly increased with ADA levels also higher than normal range along with low glucose levels consistent with the diagnosis. Viral meningoencephalitis cases revealed a mean CSF glucose of $60.11 \pm 32.28 \mathrm{mg} / \mathrm{dl}$, mean protein levels of $96.96 \pm 91.98 \mathrm{mg} / \mathrm{dl}$, mean chloride levels of113.45 \pm 14.32 meq/Lt with mean ADA level of $3.76 \pm 4.38 \mathrm{U} / \mathrm{L}$. The protein levels were higher with normal glucose levels.

\section{CSF Culture, staining and viral PCR:}

According to affordability of the patient and availability of appropriate facilities in Eastern India - CSF culture and staining, CSF viral antibody detection by ELISA (when suspected) were sent with the routine samples. Some cases were diagnosed accurately from CSF culture and ELISA that were corroborating with the clinical assumptions and radiological imaging findings.

\section{Pyogenic Meningitis etiologies:- $(N=8)$ : (See Figure 7 \& Chart 10)}

CSF gram staining and culture revealed Streptococcus pneumoniae in $4(50 \%)$ cases, Neisseria meningitides in $1(12.5 \%)$ case, Staphylococcus aureus in $1(12.5 \%)$ case and culture negative in $2(25 \%)$ cases. This shows that majority of the culture positive cases were positive for Streptococcus pneumonia followed by equal incidence of Neisseria meningitides and Staphylococcus aureus. $25 \%$ cases that were culture negative had classical symptoms which resolved with empiric antibiotics.

\section{Tuberculous Meningitis:- ( $N=14)$}

All the cases suspicious of tuberculous etiology were $\mathrm{ZN}$ smear negative. CSF culture was negative in 10 cases $(71.4 \%)$ while culture could not be done in 4 cases(28.6\%). Diagnosis had to be established on clinical features, CSF cytology, CSF biochemistry, brain imaging and therapeutic response to anti tubercular drugs.

Viral Meningoencephalitis:- $(\mathbf{N}=\mathbf{2 8})$ : (See Figure 8 \& Chart 11)
Patients with CSF cytology indicating a viral infection revealed the following viral etiologies in CSF Elisa ( $\operatorname{IgG}$ ). 10 cases $(35.72 \%)$ were positive for Herpes simplex, 3 cases $(10.72 \%)$ were positive for Varicella zoster, 4 cases $(14.28 \%)$ were positive for Japanese B while 11cases $(39.28 \%)$ were negative or indeterminate..

\section{DISCUSSION}

\section{Pyogenic Meningitis}

Acute bacterial meningitis is more common in resource-poor than resource-rich settings. Survival is dependent on rapid diagnosis and early treatment, both of which are difficult to achieve when laboratory support and antibiotics are scarce. Syamal Modi and Amit Kumar Anand in their study Phenotypic Characterization and Antibiogram of CSF Isolates in Acute Bacterial Meningitis done in a tertiary care hospital Patna (India) found that $62.3 \%$ patients were males and $37.7 \%$ were females. The gender distribution and male preponderance in disease incidence was also marked (62.5\% males and $37.5 \%$ females) in our study done in Eastern India. In our study sample size was smaller in comparison to theirs. This male predilection reported in several previous studies. [17] Similar to the study by Marjolein J. Lucas, Matthijs C. Brouwer et al (2014), ${ }^{[18]}$ patients using immunosuppressive drugs and those with asplenia, diabetes mellitus, alcoholism, or infection with immunodeficiency virus were considered immune compromised and excluded from our study. Schutte $\mathrm{CM}$, van der Meyden $\mathrm{CH}$ in their study found patients with a Glasgow coma scale (GCS) value of $>12$ had a good neurological outcome, while those with a GCS value of $\leq 8$ had a poor outcome. They concluded that the GCS value was a better prognostic indicator than high CSF protein levels ${ }^{[8]}$. In our study we adapted GCS as the criteria for clinical severity. Group A (GCS 3 to 5) was considered as most severe clinical category. Pyogenic meningitis can be accurately and rapidly diagnosed by gram staining. Some studies have reported sensitivities of $60-90 \%$ and specificities of $>97 \%$ of CSF gram staining in the diagnosis of ABM. ${ }^{[6], .}$ In our study: $50 \%$ cases were diagnosed as Streptococcus pneumoniae induced meningitis, followed by equal incidence of Neisseria meningitides and Staphylococcus aureus cases $(12.5 \%$ each) on CSF gram staining and culture 25 percentage cases did not reveal any organism on CSF culture. Negative CSF cultures are estimated to occur in $11 \%-20 \%$ of patients with bacterial meningitis. ${ }^{[19],[6]}$ However, the clinical presentation of patients with culture-positive bacterial meningitis and patients with culture-negative bacterial meningitis was reported to be similar. R Mani, S Pradhan et al in their study conducted in South India (NIMHANS), found that streptococcus pneumoniae was the most common etiological agent of community-acquired meningitis in all age groups. This 
accounting for $238(61.8 \%)$ cases in their study, reflecting a similar trend reported in an earlier study from their institute (1978-1988). ${ }^{[20]}$ Most Indian studies have also reported a high incidence of pneumococcal meningitis ${ }^{[21],[22]}$. In our study, also Streptococcus pneumonia was the most common organism isolated from CSF culture $(50 \%$ cases. Analysis of the CSF is essential, and simple techniques can enhance the yield of diagnostic microbiology. Penicillin-resistant and chloramphenicol-resistant bacteria are a considerable threat in resource-poor settings that go undetected if CSF and blood cannot be cultured.

The future rests with the provision of effective conjugate vaccines against $\mathrm{S}$ pneumoniae, Haemophilus influenzae, and Neisseria meningitides to children in the poorest regions of the World.

\section{Viral Meningoencephalitis}

Herpes simplex virus type 1 (HSV-1) is the most common cause of sporadic encephalitis (Davison et al., 2003; Mailles et al., 2007). In some recent reports from Scandinavia and central Europe, however, varicella zoster has been identified as the most common viral agent responsible for encephalitis (Cizman \& Jazbec, 1993; Studahl et al., 1998; Koskiniemi et al., 2001). ${ }^{[23]}$ A study named - Viral aetiology and clinico-epidemiological features of acute encephalitis syndrome in eastern India conducted by Rathore SK, Dwibedi B et al during April 2011 to July 2012. ${ }^{[13]}$ Blood and CSF samples of 526 AES cases were investigated by serology and/ or PCR. Viral aetiology was identified in91 (17.2\%) cases. Herpes simplex virus (HSV; types I or II) was most common (16.1\%). Simultaneous infection of HSV I and measles was observed in seven cases. This report provides the first evidence on viral aetiology of Acute encephalitis syndrome viruses from eastern India showing dominance of HSV that will be useful in informing the public health system. In our study there were majority of HSV cases. In CSF Elisa (IgG). 10 cases $(35.72 \%)$ were positive for Herpes simplex, 3 cases $(10.72 \%)$ were positive for Varicella zoster, 4 cases $(14.28 \%)$ were positive for Japanese B while $11 \operatorname{cases}(39.28 \%)$ were negative or indeterminate. So there is a similarity and etiological preponderance of HSV in both western and eastern India.

Panagariya A, Jain RS et al ${ }^{[24]}$ in a study conducted in North West India with Herpes simplex encephalitis cases included patients admitted with provisional diagnosis of an encephalitic illness over a period of 30 months. Special investigations included CSF analysis, EEG, CT scan and MRI. Herpes simplex virus (HSV) antibody estimation in CSF and blood was done simultaneously using ELISA. 28 patients showed electroencephalographic, serologic and/or neuro radiological evidence of herpes simplex encephalitis. Exact incidence of this disease (HSE) is the most difficult to estimate, because only few patients with common cause of fatal sporadic acute encephalitis with severe disease report to hospital whereas mild and self limiting cases usually go unrecognised. In India, HSE appears to be under diagnosed; probably due to lack of awareness and diagnostic facilities.CSF polymerase chain reaction (PCR) and immuno-cytochemistry could not be done in their study because of non-availability. CSF PCR is not always available in laboratories in eastern part of India, due to which it could not be done in our study. Moreover affordability was also a point of concern in case of patients attending our hospital. Japanese encephalitis (JE) is the leading cause of encephalitis in Southeast Asia, where 30,000-50,000 cases are recorded annually (Tsai, 1997). ${ }^{[25]}$ The World Health Organisation estimated nearly 14,000 deaths due to JE in the year 2002. Of these, 8,500 occurred in Southeast Asia, 3,000 in the western Pacific region and about 2,000 in the eastern Mediterranean region.

The incidence of neurologic complications associated with varicella is estimated to be $1-3$ per 10,000 cases ${ }^{[26]}$. The central nervous system (CNS) manifestations that occur most frequently with varicella are cerebellar ataxia and encephalitis ${ }^{[26]}$. The most serious CNS complication of varicella, has an incidence of 1-2 episodes per 10,000varicella cases, with the highest incidence in adults and infants. ${ }^{[27]}$ The CSF findings are usually abnormal with elevated opening pressure, a mild-to-moderate lymphocytic pleocytosis (usually $<100$ cells $/ \mu \mathrm{L})$, mildly elevated protein $(50-100 \mathrm{mg} / \mathrm{dL})$, and normal glucose levels. Dengue encephalopathy is a wellrecognized and common entity, the incidence ranging from 0.5 to $6.2 \%{ }^{[28]}$ Dengue is not classically a neurotropic virus, although there is recent evidence of direct neuronal injury. Dengue encephalitis must be thought of in differentials of encephalopathy, in patients with dengue. We found 3 such cases in our study with feature of encephalopathy who were diagnosed cases of IgM positive dengue with CSF analysis indicating a viral etiology and a normal MRI. Dengue specific IgM antibody (ELISA) was negative in 2 and could not be done in 1 case. In light of our knowledge regarding dengue encephalopathy a negative CSF antibody cannot refute its presence. So whether the encephalopathy was due to some other viral pathogen or as consequence of dengue could not be confirmed. All 3 patients survived without any residual neuro deficit or CNS complications. Infection of the CNS with the measles virus (MV) may result in 1) acute post infectious encephalitis, 2) acute progressive encephalitis, and 3) SSPE. Data about imaging findings in acute measles encephalitis are sparse. T2WI may reveal cortical edema and bilateral symmetric hyper intense lesions within the putamen and caudate nuclei as well as within the centrum semiovale. ${ }^{[29]}$ Sometimes patients also present bilateral thalamic lesions and signal abnormalities within the corpus callosum. We found 2 cases with a recent history of measles who subsequently developed features of encephalopathy. The disease was self limiting and their MRI were normal. 
We would sum up in accordance to I. Steiner, H. Budka et al and their review of diagnosis and management recommendations in Viral encephalitis. ${ }^{[30]}$. A holistic approach to diagnosis should be based on medical history, examination; followed by analysis of cerebrospinal fluid for protein and glucose contents, cellular analysis and identification of the pathogen by polymerase chain reaction (PCR) amplification(recommendation level A)and serology (recommendation level B). Lumbar puncture can follow neuroimaging when immediately available, but if this cannot be obtained at the shortest span of time it should be delayed only in the presence of strict contraindications. Brain biopsy should be reserved only for unusual and diagnostically difficult cases. All encephalitis cases must be hospitalized with an access to intensive care units. Supportive therapy is an important basis of management. Specific, evidence-based, anti-viral therapy, acyclovir, is available for herpes encephalitis (recommendation level A). Acyclovir might also be effective for varicella-zoster virus encephalitis, gancyclovir and foscarnet for cytomegalovirus encephalitis

\section{Tuberculous Meningitis}

J Kalita, UK Misra in their study evaluated the clinical and radiological outcome of tuberculous meningitis (TBM) patients. In this study most of the patients were females who were anemic.MRI revealed hydrocephalus, exudates, infarction and multiple granuloma and the majority of the patients improved following ant tubercular therapy. In our study there was a female predilection $(57.14 \%)$. Under nutrition and anaemia may be a result or risk factor for development of tuberculous meningitis. Adults with tuberculous meningitis (TBM) can often present with the classic meningitis symptoms of fever, headache and stiff neck along with focal neurological deficits, behavioural changes, and alterations in consciousness ${ }^{[31]}$. The presence of active pulmonary tuberculosis on chest $\mathrm{X}$ - ray ranges from 30 to $50 \%$. TBM may have an acute presentation. The duration of presenting symptoms may vary from 1 day to 9 months, although several cases may present with symptoms of less than 2 weeks duration. In our cases patients had a history of less than 2 weeks duration prior to admission. Cerebrovascular complications of tuberculous meningitis that occur typically as multiple or bilateral lesions in the territories of the middle cerebral artery perforating vessels are termed as tuberculous vasculopathy. Vessel pathology appears to be a consequence of its immersion in the local inflammatory exudates. Infiltrative, proliferative and necrotising vessel pathologies have been described, leading to luminal thrombosis. There is some evidence that vasospasm may mediate strokes early in the course of the disease and proliferative intimal disease later strokes ${ }^{[32]}$. In this study we encountered $28.57 \%$ cases with cerebral infarcts.

\section{SUMMARY}

This observational study was done in a tertiary care hospital of Eastern India. 50 consecutive hospital admitted patients (>12 yrs) fulfilling the inclusion criteria were randomly selected over a period of 19 months. A male preponderance was marked in Pyogenic meningitis cases while a female preponderance was noted in tuberculous meningitis and viral meningo encephalitis cases.

An increased propensity of disease occurrence was seen in age groups 31-40 yrs in pyogenic meningitis and younger age groups (12- $30 \mathrm{yrs}$ ) were more affected in tuberculous and viral meningoencephalitis. Individual patients were assessed by clinical status on admission and divided into three GCS group. 15 cases(30\%) belonged to group A(GCS 3 to 5), 22 cases(44\%) belonged to gr B(GCS 6 to 9) while 13 cases (26\%) belonged to gr C( GCS 10 to 15 ) on admission. 18 cases $(36 \%)$ were male and 32 cases(64\%) were female. Patient's ages ranging from 12 yrs to 77 yrs were selected and divided into age groups. CSF study and MRI brain was done and etiologically the cases were reclassified. Out of 50 cases 8 cases $(16 \%)$ were diagnosed as pyogenic meningitis [ 5 males $(62.5 \%)$ and 3 females(37.5\%)], 14cases $(28 \%)$ were diagnosed as tuberculous meningitis [6males (42.86\%) and 8 females (57.14\%)] and 28 cases $(56 \%)$ were diagnosed as viral meningoencephalitis [7males $(25 \%)$ and 21 females (75\%)].CSF study revealed neutrophilic picture with hypoglycorrhachia in bacterial meningitis with CSF culture studies revealing Streptococcus pneumoniae as the most commonly isolated pathogen $(50 \%$ cases $)$. Tuberculous meningitis revealed CSF lymphocytic pleocytosis with significantly increased protein and ADA levels. CSF ZN staining in all cases were negative, CSF culture for tuberculosis was negative in $71.4 \%$ cases and could not be done in $28.6 \%$ cases although the diagnosis was established on other parameters and imaging evidence.

The CSF samples of viral meningoencephalitis revealed lymphocytic picture and increased protein with majority of cases being positive for Herpes simplex antibody (in CSF by ELISA method) in $35.72 \%$. $14.28 \%$ cases were positive for Japanese B antibody. 10.72\% cases were diagnosed as Varicella zoster cases. Serological confirmation of diagnosis was not possible in other cases due to non-availability of the specific test (Viral PCR) or a negative serology in $39.28 \%$.

\section{CONCLUSION}

In this Eastern India based study viral etiologies were more frequently detected (56\%) followed by tubercular(28\%) and pyogenic(16\%) causes of disease. There was an overall female preponderance $(64 \%)$ with maximum number of patients belonging to younger age groups. Male predilection 
in pyogenic meningitis $(62.5 \%)$ and a female predilection $(57.14 \%)$ in tuberculous meningitis was noted, which was similar to several other studies done in other parts of the world. Most of the tuberculous meningitis cases (42.8\%) were clinically more severe according to the GCS category during admission followed by viral meningoencephalitis (28.57\%) and pyogenic meningitis (12.5\%).CSF cytology revealed neutrophillic picture in pyogenic and lymphocyticpleocytosis in tuberculous and viral meningoencephalitis. CSF biochemistry revealed hypoglycorrhachia in pyogenic and tuberculous meningitis and high protein levels in viral and grossly high protein content in tuberculous meningitis cases. ADA levels were also high in tuberculous meningitis.CSF gram staining, culture and serology results showed Streptococcus pneumoniae as the most common pathogen causing pyogenic meningitis(50\%) and Herpes simplex as most common viral pathogen $(35.72 \%)$ causing meningoencephalitis. This is a potential area of research and rightfully demands attention in the near future. India being a resource poor nation, improvisation of the specific diagnostic modalities and implementation with regard to affordability should be prioritised. Especially in this part of the world, there is a dearth of multicentric prospective studies on meningoencephalitis. More studies should be conducted based on correlation of clinical aspects with brain imaging; prognostication and taking into account the long term outcomes.

\section{Limitations of the study}

Sample size is small $(\mathrm{N}=50)$. This study was done over a certain catchment area, hence not a multicentric study. As the study was done in a tertiary care hospital, the mean values may not properly reflect the actual population mean. Due to small sample size and wide range of variation in the values of the CSF parameters, in certain cases the standard deviation exceeded the mean values.CSF PCR could not be done due to non-availability during that period. Empiric therapy had to be started in most of the cases prior to confirmation of diagnosis, for the sake of the patients. Some of the patients who fulfilled the inclusion criteria, had to be excluded due to economic constraints.

Conflict of interest- Authors did not have any conflict of interest.

Corresponding author: Dr. Sinjan Ghosh. Department of Neurology, Nil Ratan Sircar Medical College and Hospital,Kolktata 14, West Bengal, India

\section{REFERENCES}

1. Bandaru NR, Ibrahim MK, Nuri MS, Suliman MB. Etiology and occurrence of acute bacterial meningitis in children in Benghazi, Libyan Arab Jamahiriya. East Mediterr Health J. 1998; 4:50-7.

2. Bloch KC, Glaser C. Diagnostic approaches for patients with suspected encephalitis. Curr Infect Dis Rep. 2007; 9(4):315-22.
3. Khan F, Rizvi M, Fatima N, Shukla I, Malik A, Khatoon R. Bacterial meningitis in North India: Trends over a period of eight years. Neurology Asia. 2011;16(1):47-56.

4. Rozenberg, F; Deback C; Agut H (June 2011). "Herpes simplex encephalitis: from virus to therapy". Infectious Disorders Drug Targets 11 (3): 235-250

5. D C Hughes, A Raghavan, S R Mordekar, P D Griffiths, D J A Connolly.Role of imaging in the diagnosis of acute bacterial meningitis and its complications. Postgrad Med J .2010;86:478485.

6. Durand ML, Calderwood SB, Weber DJ, Miller SI, Southwick FS et al. Acute bacterial meningitis in adults. A review of 493 episodes. N Engl J Med. 1993;328:21-28.

7. BeggN Cartwright, KAV , Cohen J., Kaczmarski, EB . Innes, JA. Leen, CLS et al .Consensus statement on diagnosis, investigation, treatment and prevention of acute bacterial meningitis in immunocompetent adults. Journal of Infection [J. Infect.]. 1999; 39: 1-15.

8. Schutte CM, van der Meyden CH.A prospective study of Glasgow Coma Scale (GCS), age, CSF-neutrophil count, and CSFprotein and glucose levels as prognostic indicators in 100 adult patients with meningitis.J Infect. 1998;37(2):112-5.

9. Syamal Modi, Amit Kumar Anand. Phenotypic Characterization and Antibiogram of CSF Isolates in Acute Bacterial Meningitis. J Clin Diagn Res. 2013; 7(12): 2704-2708.

10. Mani R, Pradhan S, Nagarathna S, Wasiulla R, Chandramuki A. Bacteriological profile of community acquired acute bacterial meningitis: A ten-year retrospective study in a tertiary neurocare centre in South India. Indian J Med Microbiol 2007;25:108-14

11. Tang LM, Chen ST, Hsu WC, Lyu RK. Acute bacterial meningitis in adults: A hospital-based epidemiological study. QJM 1999; $92: 719-25$.

12. Domingues R.B., Fink M.C.D., Tsanaclis A.M.C., de Castro C.C., Cerri C.C., Mayo M.S., et al.Diagnosis of herpes simplex encephalitis by magnetic resonance imaging and polymerase chain reaction assay of cerebrospinal fluid. J NeurolSci. 1998; 157:148-153.

13. Rathore SK, Dwibedi B, Kar SK, Dixit S, Sabat J, Panda M. Viral aetiology and clinico-epidemiological features of acute encephalitis syndrome in eastern India. Epidemiol Infect. 2014; $24: 1-8$.

14. Satishchandra P, Ravi V, Shankar SK : Herpes simplex encephalitis : Clinicopathological and virological appraisal. Progress in Clinical Neuro Sciences1996; 11 : 167-186.

15. Coren ME, Buchdahl RM et al : Imaging and laboratory investigation in herpes simplex encephalitis. J NeurolNeurosurg Psychiatry1999; $67: 243-245$.

16. Frantzidou, F., Kamaria, F., Dumaidi, K., Skoura, L., Antoniadis, A. and Papa, A. (2008), Aseptic meningitis and encephalitis because of herpesviruses and enteroviruses in an immunocompetent adult population. European J Neurol, 15: 995-997.

17. Pfister HW, Feiden W, Einhaupl KM. Spectrum of complications during bacterial meningitis in adults: results of a prospective clinical study. Arch Neurol. 1993;50:575-81.

18. Marjolein J. Lucas, Matthijs C. Brouwer, ,Arie van der Ende and Diederik van de Beek. Outcome in patients with bacterial meningitis presenting with a minimal Glasgow Coma Scale score. Neurol Neuroimmunol.2014;1: 1 e9.

19. Pfister HW, Feiden W, Einhaupl KM. Spectrum of complications during bacterial meningitis in adults: results of a prospective clinical study. Arch Neurol. 1993;50:575-81.

20. Chandramukhi A. Neuromicrobiology. In: Neurosciences in India: Retrospect and Prospect . The Neurological Society of India, Trivandrum and CSIR: New Delhi; 1989. p. 361-95. 
21. Kabra SK, Praveen Kumar, Verma IC, Mukherjee D, Chowdhary $\mathrm{BH}$, Sengupta S, et al . Bacterial meningitis in India: An IJP survey. Indian J Pediatr 1991; $58: 505-11$.

22. Chinchankar N, Mane M, Bhave S, Bapat S, Bavdekar A, Pandit A, et al . Diagnosis and outcome of acute bacterial meningitis in early childhood. Indian Pediatr 2002; 39 :914-21.

23. Misra, U. K., Tan, C. T. and Kalita, J. Viral encephalitis and epilepsy.Epilepsia 2008; 49: 13-18.

24. Panagariya A, Jain R S, Gupta S, Garg A, Sureka R K, Mathur V. Herpes simplex encephalitis in North West India. Neurol India 2001;49:360

25. Tsai TF, Chang GJ, Yu XY. Japanese encephalitis vaccine. In: Plotkins SA, Orenstein WA, editors. Vaccines. Philadelphia: W.B. Saunders; 1999. p. 684-710.

26. Applebaum E, Rachelson MH, Dolgopol VB. Varicella encephalitis. Am J Med 1953;15:223-30.

27. Choo PW, Donahue JG, Manson JE, Plott R. The epidemiology of varicella and its complications. J Infect Dis 1995;172:706-12.

\section{SEX DISTRIBUTION}

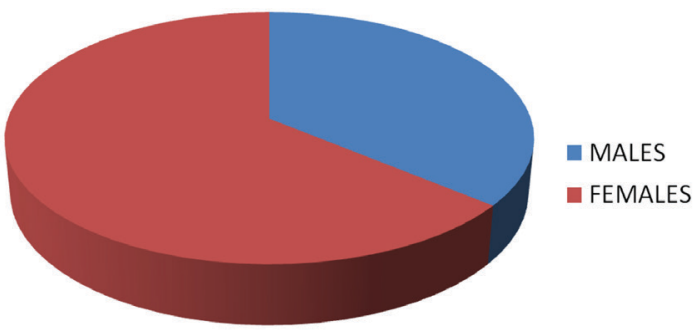

Chart 1: Sex Distribution.

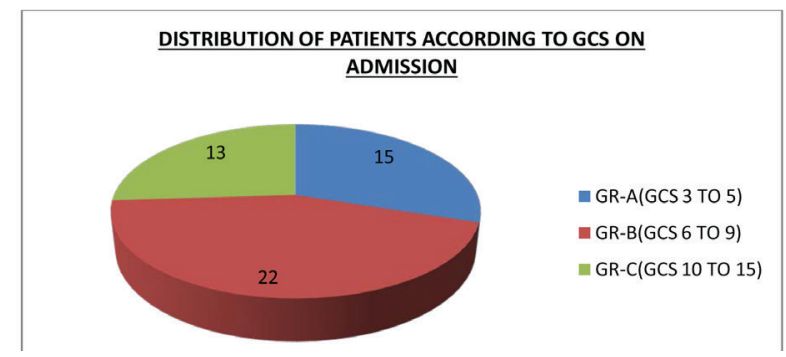

Chart 2: Distribution of Patients according to GCS on admission.

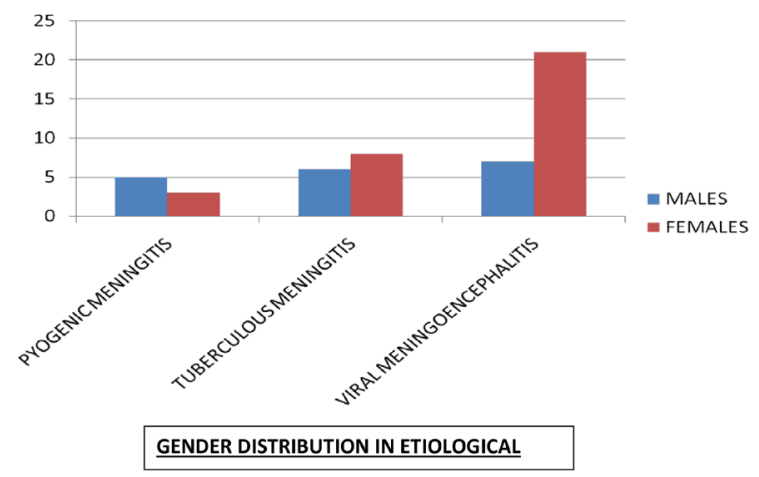

Chart 3: Gender Distribution in Etiological.
28. Misra UK, Kalita J, Syam UK, Dhole TN. Neurological manifestations of dengue virus infection. J Neurol Sci. 2006;244:11722

29. Lee KY, Cho WH, Kim SH, Kim HD, Kim IO. Acute encephalitis associated with measles: MRI features. Neuroradiology.2003; 45: 100-106.

30. I. Steiner, H. Budka, A. Chaudhuri, M. Koskiniemi, K. Sainio, O. Salonen et al. Viral encephalitis: a review of diagnostic methods and guidelines for management. European Journal of Neurology2005; 12: 331-343.

31. Sutlas PN, Unal A, Forta H, Senol S, Kirbas D. Tuberculous meningitis in adults: Review of 61 cases. Infection. 2003;31:387391.

32. Lammie GA, Hewlett RH, Schoeman JF, Donald PR. Tuberculous cerebrovascular disease: A Review. J Infect. 2009;59:156166.

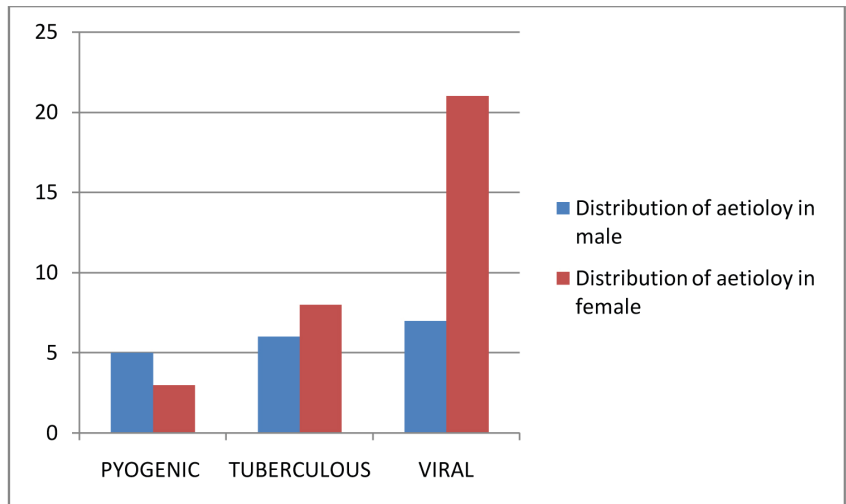

Chart: 4: Distribution of aetiology in male and female.

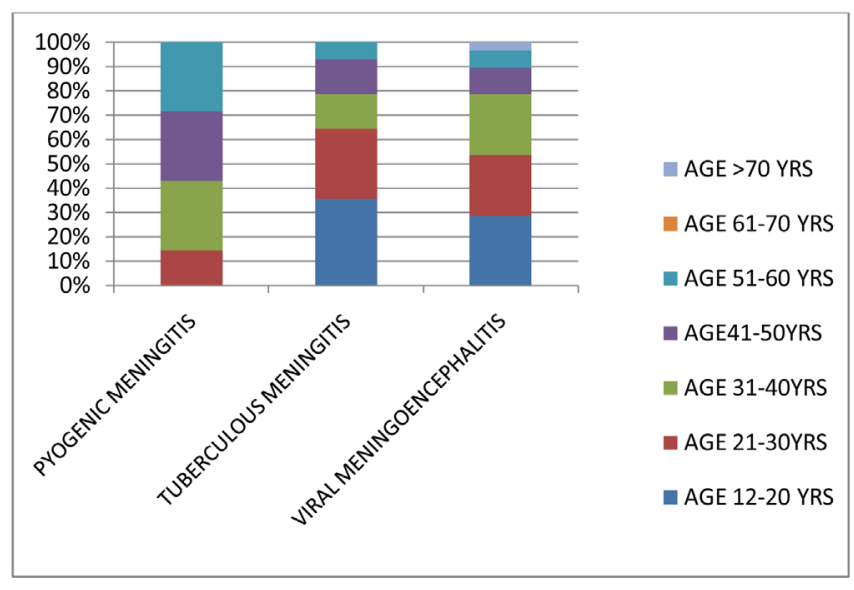

Chart 5: Distribution According to Age Groups. 


\section{PYOGENIC MENINGITIS-CLINICAL GROUPS ACCORDING TO GCS ON ADMISSION}

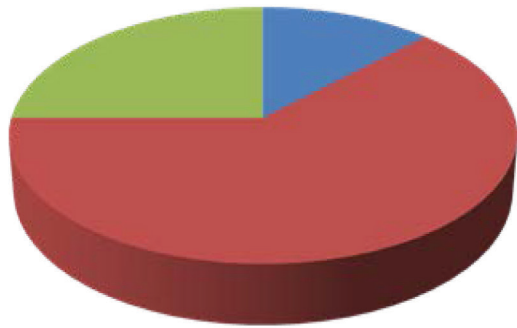

GR-A(GCS3 TO 5)

- GR-B(GCS6 TO 9)

GR-C (GCS 10 TO

15)

Chart 6: Clinical Group according to GCS on admission in Pyogenic Meningitis.

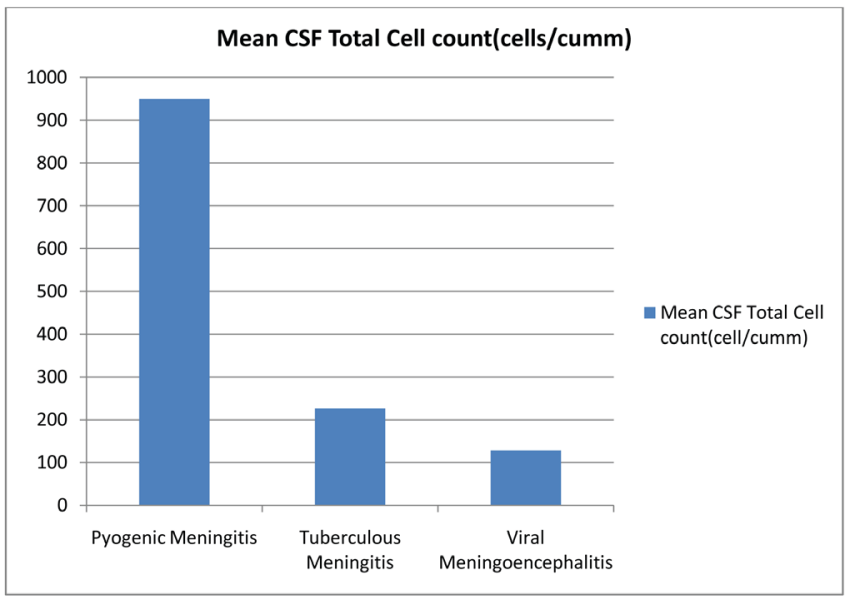

Chart 7: Mean CSF Total Cell.

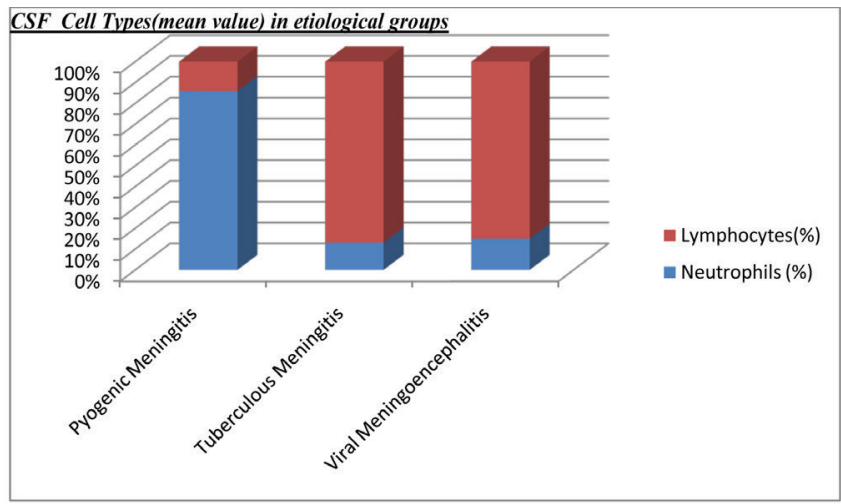

Chart 8: CSF cell type in etiological group.

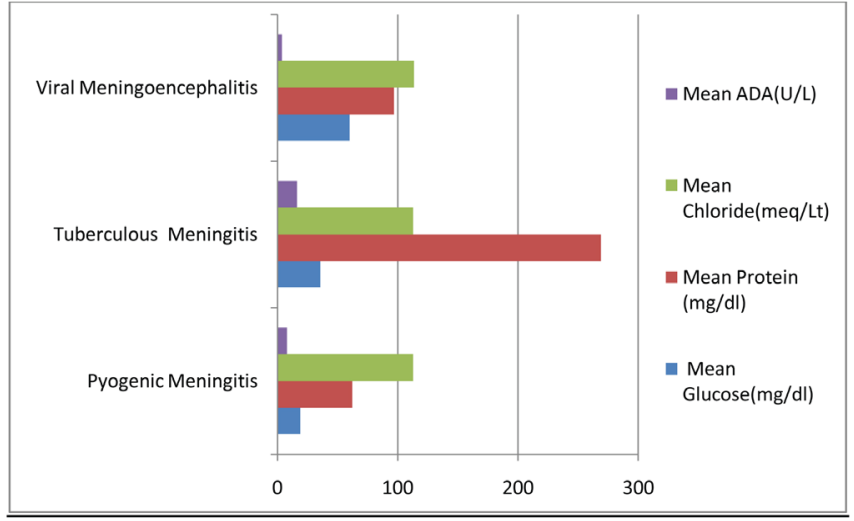

Chart 9: CSF BIOCHEMISTRY and ADA levels.

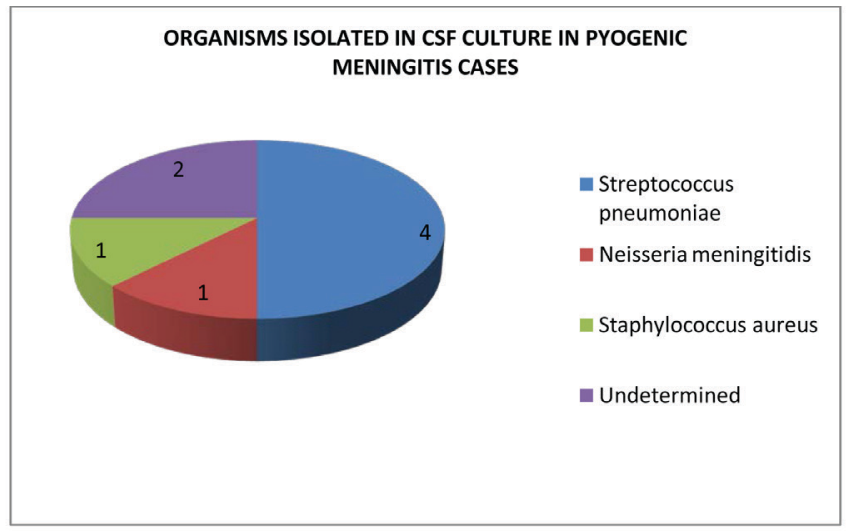

Chart 10: Organism isolated in CSF culture in pyogenic meningitis.

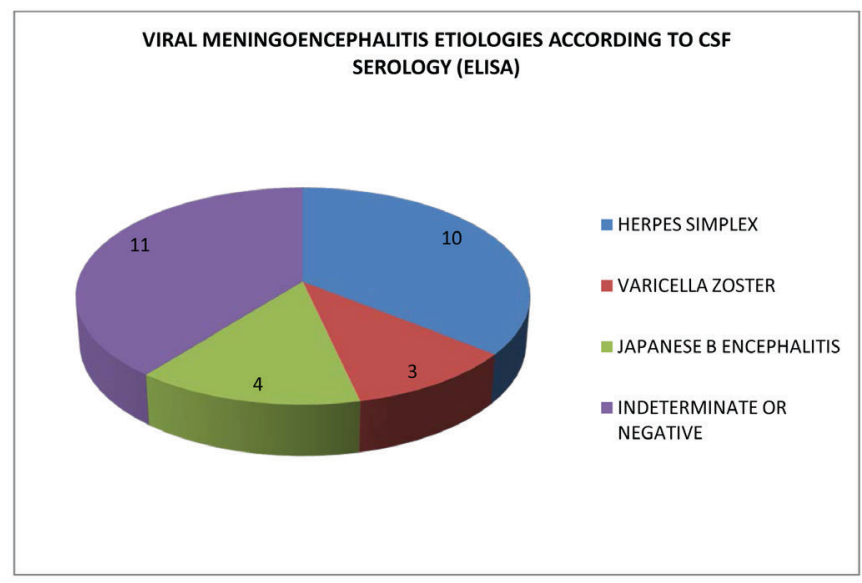

Chart-11: Viral meningoencephalitis according to CSF serology 
Table 1: Distribution According to Age Groups

\begin{tabular}{|c|c|}
\hline \multicolumn{2}{|c|}{ Distribution According to Age Groups } \\
\hline Age Groups (In Years) & Number of Patients $(\mathrm{N}=50)$ \\
\hline 12 to 20 & 13 \\
\hline 21 to 30 & 12 \\
\hline 31 to 40 & 12 \\
\hline 41 to 50 & 07 \\
\hline 51 to 60 & 05 \\
\hline 61 to 70 & o \\
\hline$>71$ & O1 \\
\hline
\end{tabular}

Table 2: Gender Distribution in Etiological Groups and Percentages

\begin{tabular}{|c|c|c|c|c|}
\hline Etiology & Total Numbr & $\begin{array}{l}\text { Males } \\
(\mathrm{N}=18)\end{array}$ & $\begin{array}{c}\text { Females } \\
(\mathrm{N}=32)\end{array}$ & $\begin{array}{l}\text { Percentage } \\
(\%)\end{array}$ \\
\hline Pyogenicmeningitis & 8 & 5 & 3 & $\begin{array}{c}\text { Males- } 62.5 \\
\text { Females- } 37.5\end{array}$ \\
\hline $\begin{array}{l}\text { Tuberculous } \\
\text { Meningitis }\end{array}$ & 14 & 6 & 8 & $\begin{array}{c}\text { Males- } 42.86 \\
\text { Females- } 57.14\end{array}$ \\
\hline $\begin{array}{l}\text { Viral } \\
\text { Meningoencephalitis }\end{array}$ & 28 & 7 & 21 & $\begin{array}{l}\text { Males- } 25 \\
\text { Females- } 75\end{array}$ \\
\hline
\end{tabular}

Table 3: Distribution According to Age Groups

\begin{tabular}{|c|c|c|c|c|}
\hline Etiology & $\begin{array}{l}\text { Age Groups of Patients } \\
\text { (In Years) }\end{array}$ & Number of Patients & Mean Age & Percentage (\%) \\
\hline \multirow{7}{*}{$\begin{array}{l}\text { Pyogenic } \\
\text { Meningitis }\end{array}$} & 12 to 20 & o & - & - \\
\hline & 21 to 30 & 1 & 25 & 12.5 \\
\hline & 31 to 40 & 3 & 37 & 37.5 \\
\hline & 41 to 50 & 2 & 44 & 25 \\
\hline & 51 to 60 & 2 & 52 & 25 \\
\hline & 61 to 70 & o & - & - \\
\hline & $>70$ & o & - & - \\
\hline \multirow{7}{*}{$\begin{array}{l}\text { Tuberculous } \\
\text { Meningitis }\end{array}$} & 12 to 20 & 05 & 16.8 & $35 \cdot 71$ \\
\hline & 21 to 30 & 04 & 27 & 28.57 \\
\hline & 31 to 40 & 02 & 38 & 14.28 \\
\hline & 41 to 50 & 02 & 44.5 & 14.28 \\
\hline & 51 to 60 & 01 & 53 & 07.1 \\
\hline & 61 to 70 & o & - & - \\
\hline & $>70$ & o & - & - \\
\hline \multirow{7}{*}{$\begin{array}{l}\text { Viral } \\
\text { Meningo } \\
\text { Encephalitis }\end{array}$} & 12 to 20 & 08 & 15.63 & 28.57 \\
\hline & 21 to 30 & 07 & 25 & 25 \\
\hline & 31 to 40 & 07 & 36 & 25 \\
\hline & 41 to 50 & 03 & 44.33 & 10.71 \\
\hline & 51 to 60 & 02 & 54 & 07.41 \\
\hline & 61 to 70 & o & - & - \\
\hline & $>70$ & o1 & 77 & 03.57 \\
\hline
\end{tabular}


Table 4: Classification According to GCS in Different Etiological Groups

\begin{tabular}{|c|c|c|c|c|}
\hline $\begin{array}{l}\text { Clinical groups } \\
\text { (glasgow coma scale/ gcs) }\end{array}$ & $\begin{array}{l}\text { Number of pa- } \\
\text { tients according to } \\
\text { clinical severity on } \\
\text { admission }\end{array}$ & $\begin{array}{c}\text { Pyogenic } \\
\text { Meningitis } \\
(n=8)\end{array}$ & $\begin{array}{c}\text { Tuberculous } \\
\text { Meningitis } \\
(n=14)\end{array}$ & $\begin{array}{c}\text { Viral } \\
\text { Meningo } \\
\text { encephlitis } \\
(\mathbf{n}=\mathbf{2 8})\end{array}$ \\
\hline Group - A(GCS: 3 to 5$)$ & 15 & 1 & 6 & 8 \\
\hline Group - B(GCS: 6 to 9) & 22 & 5 & 6 & 11 \\
\hline Group - C(GCS: 10 to 15) & 13 & 2 & 2 & 9 \\
\hline Aetiological group & \multicolumn{2}{|c|}{ CSF - total cell count (mean) } & $\begin{array}{l}\text { Neutrophils } \\
\text { (mean) }\end{array}$ & $\begin{array}{l}\text { Lymphocytes } \\
\text { (mean) }\end{array}$ \\
\hline Pyogenic meningitis & \multicolumn{2}{|c|}{$950.5 \pm 3748.84$} & $85.88 \pm 25.18$ & $14.13 \pm 25.18$ \\
\hline Tuberculous meningitis & \multicolumn{2}{|c|}{$225.86 \pm 217.22$} & $13.14 \pm 32.8$ & $86.86 \pm 32.8$ \\
\hline Viral meningoencephalitis & \multicolumn{2}{|c|}{$128.61 \pm 276.86$} & $14.93 \pm 25.14$ & $85.07 \pm 25.14$ \\
\hline
\end{tabular}

Table 6: CSF Biochemistry and ADA Levels in Different Etiolgical Groups

\begin{tabular}{lllll} 
Etiological Group & $\begin{array}{l}\text { CSF Glucose } \\
(\text { Mean) }\end{array}$ & $\begin{array}{l}\text { CSF Protein } \\
(\text { Mean) }\end{array}$ & $\begin{array}{l}\text { CSF Chloride } \\
(\text { Mean })\end{array}$ & $\begin{array}{l}\text { CSF ADA Levels } \\
\text { Mean }\end{array}$ \\
Pyogenic Meningitis & $19 \pm 18.9$ & $62.375 \pm 48.52$ & $112.88 \pm 12.48$ & $8.03 \pm 24.14$ \\
Tuberculous Meningitis & $35.79 \pm 22.9$ & $268.86 \pm 368.12$ & $112.71 \pm 12.54$ & $16.29 \pm 16.14$ \\
Viral Meningoencephalitis & $60.11 \pm 32.28$ & $96.96 \pm 91.98$ & $113.45 \pm 14.32$ & $3.76 \pm 4.38$ \\
\hline
\end{tabular}

Table 7: Organisms Isolated in CSF Culture of Pyogenic Meningitis Cases

\begin{tabular}{llcc} 
S1. No. & Organisms isolated in CSF culture in Pyogenic Meningitis & $\begin{array}{c}\text { Number of case } \\
(\mathrm{N}=8)\end{array}$ & $\begin{array}{c}\text { Percentage } \\
(\%)\end{array}$ \\
1. & Streptococcus pneumoniae & 4 & 50 \\
2. & Neisseria meningitidis & 1 & 12.5 \\
3. & Staphylococcus aureus & 1 & $\mathbf{2}$ \\
4. & Undetermined/Negative & 25 & 25 \\
\hline
\end{tabular}

Table 8: Confirmed viral Aetiology

\begin{tabular}{lcc} 
Etiology confirmed on CSF ELISA & Number of patients $(\mathrm{N}=28)$ & Percentage(\%) \\
Herpes Simplex & 10 & 35.72 \\
Japanese B & 04 & 14.28 \\
Varicella Zoster & 03 & 10.72 \\
Negative/Indeterminate & 11 & 39.28 \\
\hline
\end{tabular}

